\title{
Vascular surgery of the posterior tibial compartment for plantar ulceration in leprosy
}

\author{
SATISH K. AROLKAR \& NOSHIR H. ANTIA \\ The Foundation for Medical Research 84-A, R.G. Thadani Marg \\ Worli, Bombay 400 018, India
}

Accepted for publication 26 October 1994

\begin{abstract}
Summary Traditional surgical decompression of the posterior tibial nerve yields equivocal results. The authors postulate that the posterior tibial artery is the most compromised structure in the neurovascular compartment and that the best surgical results in healing of plantar ulcers are achieved by the rechannelling of the blood flow in the posterior tibial artery during posterior tibial neurovascular compartment surgery.

This procedure has been of benefit to patients with plantar ulcers of greater than 7-10 years' duration in whom all other modes of healing had failed. It has been undertaken as an outpatient procedure under local anaesthesia, supported by postoperative vasodilator drugs. The use of tourniquet, antibiotics and surgical interference with the ulcer per se was eschewed. A report of 156 patients is presented with follow-up of up to 6 years for the earlier cases.
\end{abstract}

\section{Introduction}

Recurrent plantar ulceration of the anaesthetic foot is a severely disabling deformity in leprosy, the most severe deformity leading to loss of toes. This presents a difficult problem in the rehabilitation of these patients and may even necessitate amputation. According to Srinivasan ${ }^{1} 10-15 \%$ of leprosy patients suffer from neuropathic plantar ulceration. Ulceration also occurs in other neuropathies like diabetes mellitus, syringomyelia, tabes dorsalis and alcoholic peripheral neuropathy.

The commonest form of treatment for plantar ulceration has been evaluation and rest. A Plaster of Paris (POP) cast for 6-8 weeks heals most superficial ulcers. ${ }^{12}$ Curettage and debridement of the ulcer followed by a plaster cast is employed for deeper ulcers.

Radical metatarsectomy for deep ulcers over the 2nd, 3rd and 4th metatarsal heads ${ }^{13,14}$ and also protective footwear for leprosy patients was described by Robertson ${ }^{15}$ and Antia et al. ${ }^{16}$

The importance of damage to the posterior tibial nerve as a cause of anaesthesia has been well documented. Decompression of the nerve in the neurovascular compartment has given equivocal results even though this was regarded as the most important site for surgical intervention as far back as the mid 1970s. ${ }^{2}$ However, in 1955 Dharmendra et al. ${ }^{5}$ 
stated that a reduction in blood supply was an important factor in plantar ulceration, and Chatter jee ${ }^{7}$ also suggested that neurological symptoms in leprosy were not so much due to uncomplicated Wallerian degeneration as to reduced neural circulation.

Vascular changes in leprosy have been documented in the literature. Terminal arteritis and vasculitis of vasa nervorum was described by Mitsuda. ${ }^{6}$ Carayon's ${ }^{3}$ studies of the posterior tarsal and calcaneal canals demonstrated venous hyperplasia and hypertrophy around the nerve. Cochrane $\&$ Davey $^{8}$ postulated that neuroparesis of the arterial wall in leprosy led to flaccidity, and the slowing of circulation with associated tortuosity due to external compression. Carayon ${ }^{3}$ also demonstrated improvement of the 'spastic' state of the posterior tibial artery by unroofing the tarsal tunnel. However, he found that decompression of the vessel was ineffective in the presence of endovascular obstruction. Debi et al. ${ }^{9}$ reported obliteration of the vascular lumen in 5 out of 20 lepromatous leprosy cases with plantar ulceration of over 2 year's duration. There was a correlation between the age of the patients, the duration of the ulcer and arteriographic findings, so they concluded that advanced vascular changes in distal digital vessels had contributed to ischemia and ulceration. Agarwal ${ }^{10}$ performed percutaneous arteriography and muscle biopsy, finding tapering, occlusion and tortuosity of vessels with absence of collaterals. He considered that vascular thickening, perivascular granuloma and lymphocytic infiltration in the smooth muscle of the artery might be responsible for trophic ulceration.

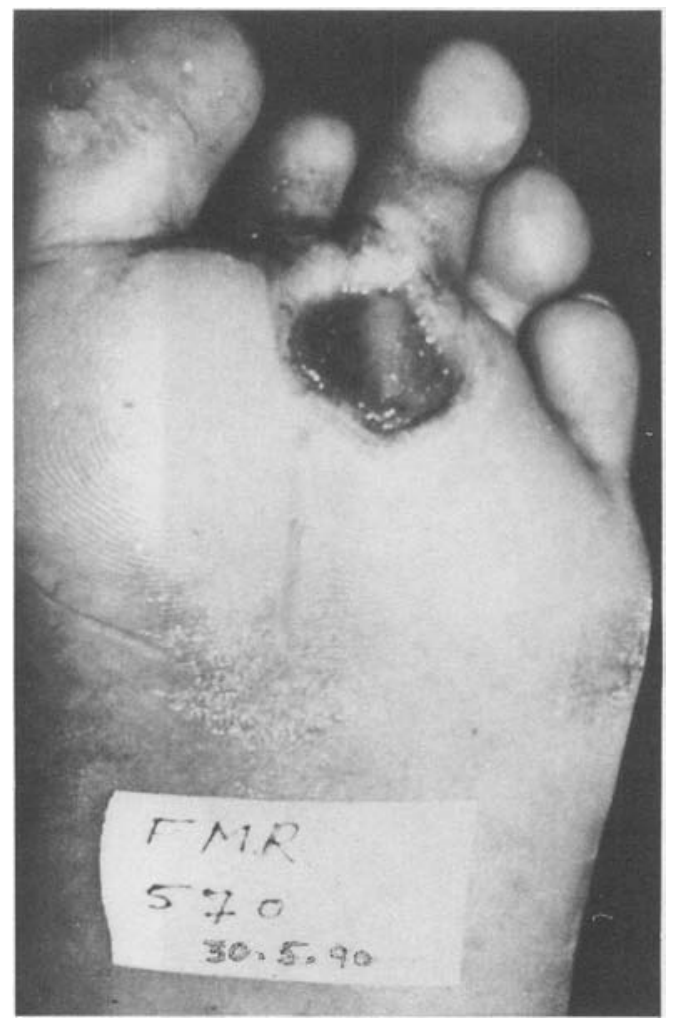

(a)

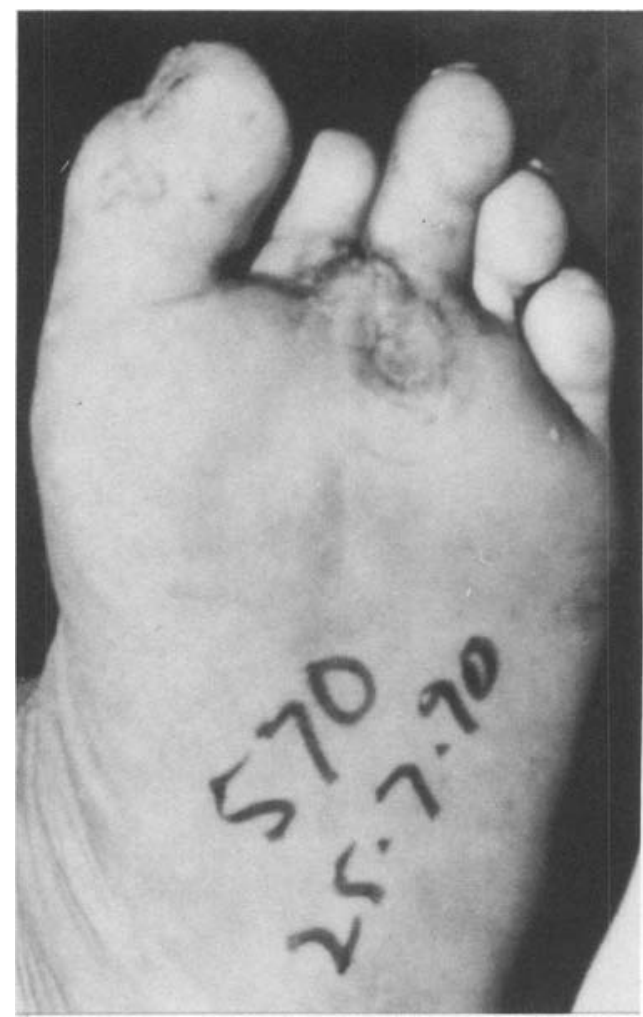

(b)

Figure 1. (a) Preoperative; (b) postoperative (9 weeks) view of plantar ulcer. 
There is thus increasing evidence in the literature of a shift in emphasis from a neural to a vascular aetiology of plantar ulceration. Possibly both factors should be considered.

In September 1984 Arolkar devised an entirely different surgical approach, based on the posterior tibial artery rather than on the nerve, and the details follow.

\section{Method}

Arolkar's surgical approach was undertaken as an outpatient procedure under local anaesthesia and without the use of a tourniquet. The dissection can be undertaken without an operating microscope. The traditional postoperative use of a POP

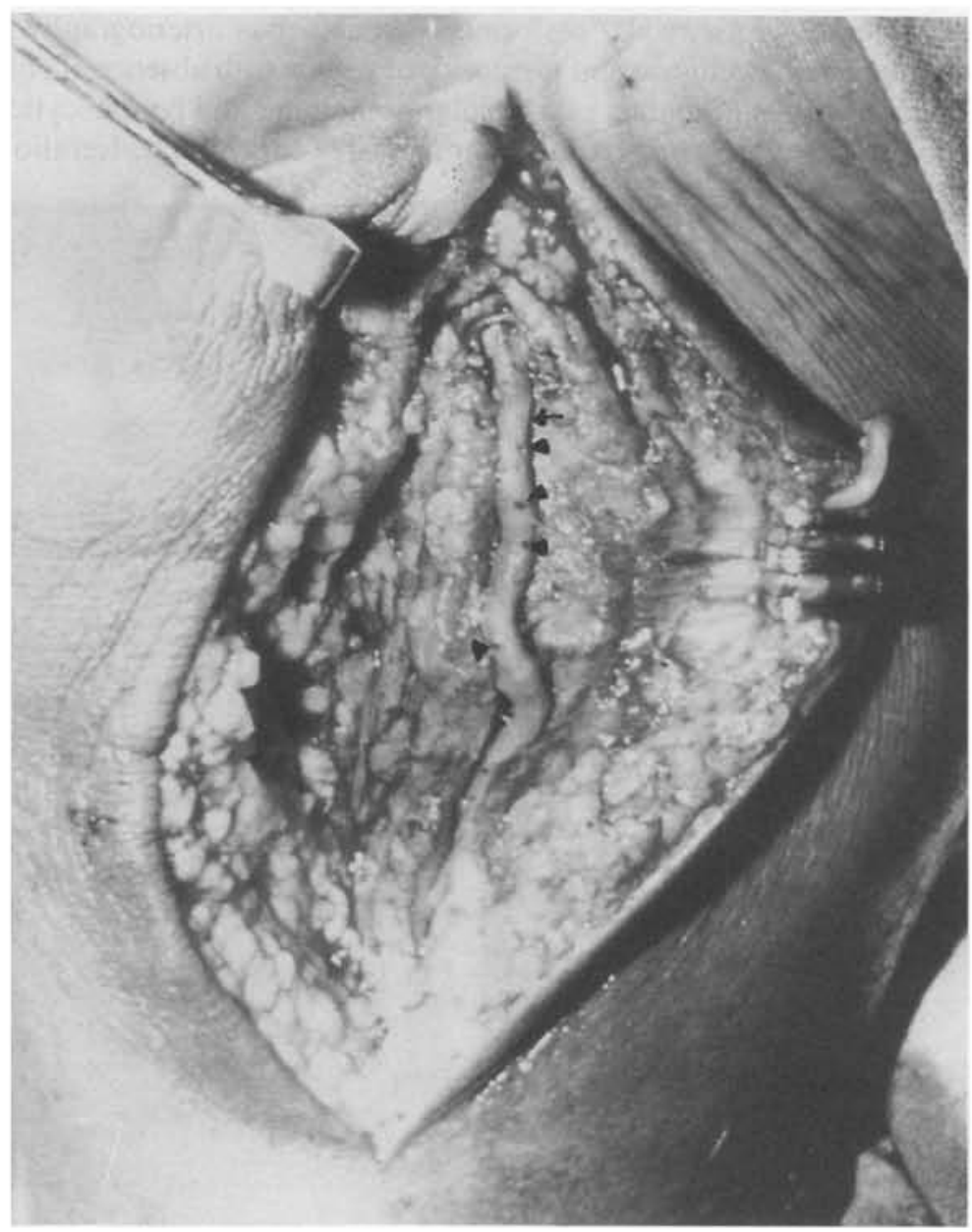

Figure 2. Operative field showing the freed posterior tibial artery $(\rightarrow)$ with some of its branches cauterized $(\triangleright)$. 
immobilization for 3-6 weeks has been reduced to 1 week, followed by the use of the patient's usual footwear postoperatively. Oral vasodilators like isoxprine were prescribed from 6 weeks to 6 months after surgery. No antibiotic is used even in the presence of active ulceration (Figure 1).

To date 156 ulcerated feet have been treated using this technique.

\section{PREOPERATIVE PREPARATION}

The foot and the ulcer are cleaned with soap and water only. No physiotherapy is prescribed.

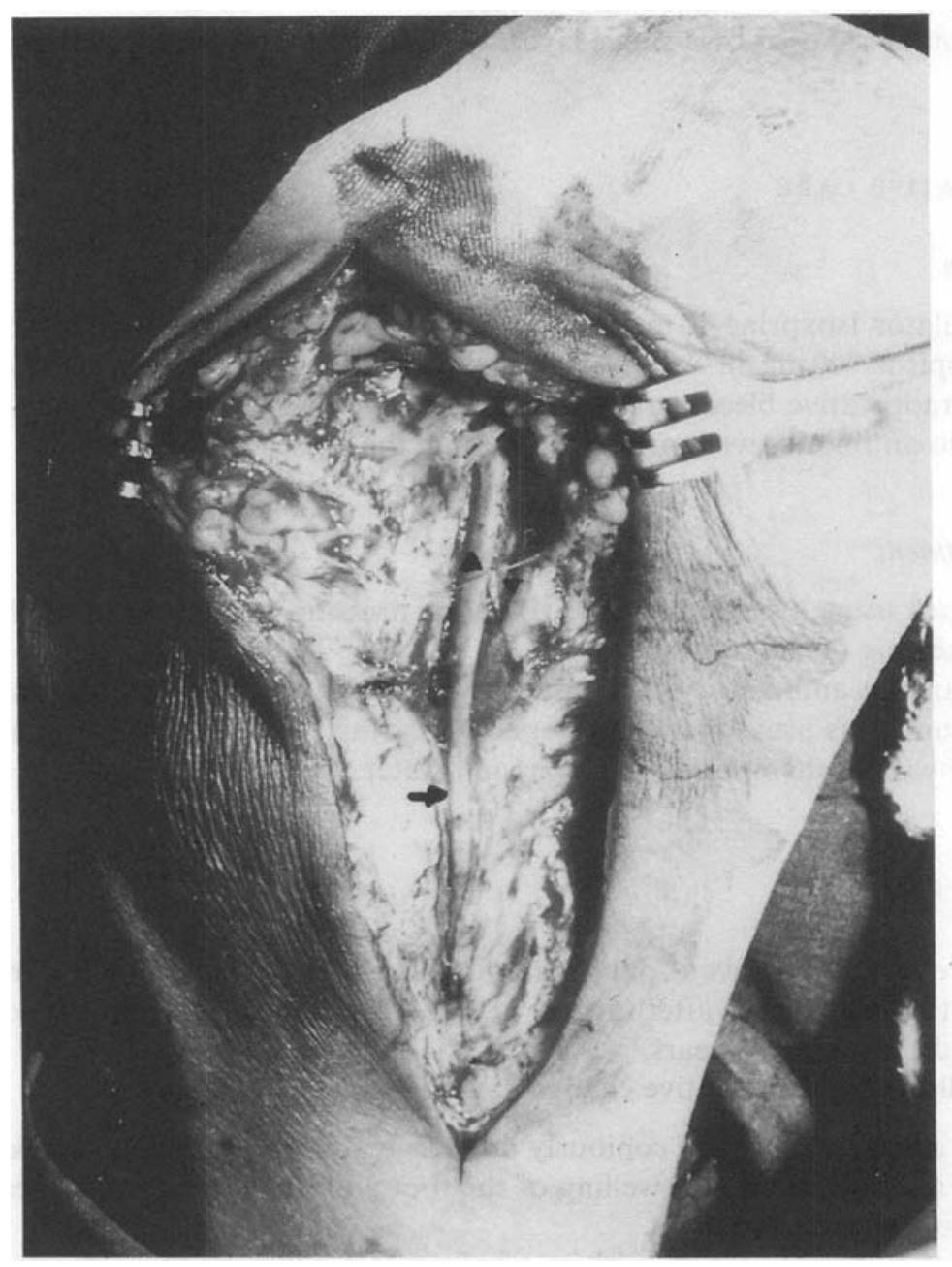

Figure 3. Operative field showing the vein $(\triangleright)$ straddling the posterior tibial artery $(\rightarrow)$ at its bif urcation above the mouth of the tarsal tunnel. 
SURGICAL TECHNIQUE

Local anaesthesia, $1 \%$ xylocaine with adrenaline $(1: 2,000,000)$ was infiltrated midway between the medial malleolus and heel, from $4.2 \mathrm{~cm}$ below to $8.5 \mathrm{~cm}$ above the medial malleolus. The posterior tibial neurovascular compartment was exposed by incising the flexor retinaculum. A longitudinal strip 1-cm wide of the thickened sheath overlying the neurovascular compartment is dissected out and excised. Care is taken to avoid any interference with the nerve or its vascularization from the underlying bed. The posterior tibial artery is completely separated from the accompanying nerve, and from its bed. All the branches varying from 8 to 14 in number along the entire exposed length of this segment of the artery are cauterized in continuity up to the bifurcation of the vessel into the medial and lateral plantar divisions in the tarsal canal (Figure 2). A vein, which is consistently observed to straddle the bifurcation, and possibly obstruct the arterial blood flow (Figure 3), is ligated and divided.

The wound is closed by a single layer subcuticular suture which is removed 6 weeks later.

POSTOPERATIVE CARE

\section{Medication}

The vasodilator Isoxprine $40 \mathrm{mg}$ is given orally in 4 divided doses daily, together with soluble Aspirin $700 \mathrm{mg}$ in 4 divided doses. If used preoperatively these drugs cause intense intraoperative bleeding and hence were given only postoperatively, for up to 6 months. No antibiotics were prescribed despite the presence of ulcers.

\section{Local treatment}

A plaster cast using a single roll of POP on the dressing is maintained for 1 week. This helps the healing of the sutureline.

The patient is ambulatory $48 \mathrm{~h}$ postoperatively. After removal of the plaster cast the patient resumes his usual footwear, possibly wearing socks. No dressings are used and the patient washes the wound with soap and water.

\section{Results}

Table 1 provides the relevant data regarding the size (a), site (b) and duration (c) of ulcers and the healing time after surgery (d). The shortest postoperative follow-up was 6 months and the longest 6 years.

The following postoperative changes were observed:

There was drying of previous copiously discharging ulcers within 2-3 weeks.

There was a reduction in the swelling of the foot and therefore a subsequent ability to wear previously worn footwear.

The foot felt warmer to touch, with re-emergence of 'filled' veins on the dorsum of the foot. 
Table 1

(a)

\begin{tabular}{ll} 
Size of ulcer & $<3 \mathrm{~cm}$ diam -51 cases \\
& $>3 \mathrm{~cm}$ diam -105 cases \\
Total number of ulcers & -156 \\
\cline { 2 - 2 } & \\
Site of ulcers & -138 cases \\
Foref oot & -12 cases \\
Lateral border of the foot & -6 cases \\
Heel & -15
\end{tabular}

(c) Duration of ulceration (years)

\begin{tabular}{lcc} 
po. of & patients & $\begin{array}{c}\text { Postoperative } \\
\text { healing time (weeks) }\end{array}$ \\
\hline $0-5$ & 51 & $3-5$ \\
$5-10$ & 73 & $4-6$ \\
$>10$ & 32 & $>6$ and more
\end{tabular}

(d) Duration of postoperative follow-up

6 months -2 years

Patients

24

$\begin{array}{ll}2 \text { years }-4 \text { years } & 58 \\ 4 \text { years-6 years } & 74\end{array}$

Chronic recurrent ulcers of up to 15-year's duration healed within 8-10 weeks without resort to split-skin grafts of flaps, utilizing the footwear used preoperatively. This was usually plastic footwear sold in the open market.

Because of an underlying necrotic bony tissue (which was confirmed by X-rays) 30 deep ulcers failed to heal postoperatively. (All ulcerated feet were not routinely X-rayed before surgery.) All but 2 of these ulcers healed by the 6th month with daily dry dressings.

The 2 cases with persistant ulceration and fungation after up to 6 months of conservative treatment had a below the knee amputation, squamous cell carcinoma being suspected and later confirmed histologically.

\section{Conclusion}

The experience of 156 cases to date suggests the probable importance of a combination of: 1 , decompression of the neurovascular compartment by excision of the sheath; 2 , sympathetic denervation of the posterior tibial vessels; and 3, selective diversion of the blood supply to the sole of the foot, by cauterizing branches of the posterior tibial artery, the last possibly playing the most significant role.

The operation has shown consistent results and its simplicity merits its use as a procedure of choice in the rehabilitation of those suffering from chronic plantar ulceration due to leprosy. Its use in other conditions, e.g. diabetes, has been beneficial especially to limit gangrene. 
In order to provide a better understanding of the scientific basis of these results, in future we propose to correlate the clinical findings with studies of motor and sensory nerve conduction as well as measuring alterations in blood flow and vascularity of the foot. Raised skin temperature would also reflect increased vascularity and is measurable.

If increased vascularity is proven, the reason for this requires further physiological investigation since reducing the peripheral field of distribution of an artery by ligating branches may not automatically increase the flow in the parent stem vessel.

\section{References}

${ }^{1}$ Srinivasan H. Neuropathic ulcers in leprosy. Surgery and management of insensitive hands and feet in leprosy. Workshop Bulletin conducted in June at CLT \& RI Chengalpattu (T.N.) sponsored by WHO and DGHS India.

2 Bourrel $\mathrm{P}$ et al. Traitement des mans perforants plantaires lepreux-interest de la nerolyse du nerf tibial posterieur au canal tarsien. Acta Leprol, 1970; 40/41: 91-4.

3 Carayon A. Investigations on the physiopathology of the nerve in leprosy. Int Jr Lep, 1971; $39: 278$.

4 Palande D. Surgical decompression of posterior tibial neurovascular complex in treatment of certain chronic plantar ulcers and posterir tibial neuritis in leprosy. Int $J$ Lep, 1975, 43: 36-40.

5 Dharmendra, Chatterji SN, Sen NR. A by-product of DDS for treatment of trophic ulcers in leprosy. Leprosy in India, 1955; 7: 180-5.

${ }^{6}$ Mitsuda. 150 autopsies of cases of leprosy. Int J Lepr, 1937; 5: 33.

7 Chatter jee SN Mechanisms of neural signs and symptoms of leprosy. Int J Lepr, 1955; 23 : 1-18.

8 Cochrane RG, Davey TF. (1964) Lesions of the neuropathic foot. Leprosy in Theory and Practice. 2nd Ed. p. 514. John Wright \& Sons, Bristol.

9 Debi BP et al. Arteriographic pattern of plantar ulcers in lepromatous leprosy-study of 20 cases. Lepr India, 1980; 52: 429-32.

10 Agarwal BR. Arteriography in leprosy. Le pr India, 1985: 57: 138-43.

11 Bose DN. Trophic ulcers in leprosy (48 cases treated by Plaster of Paris cast). Lepr India, 1956; 28: 77-9.

12 Fischer C. Treatment of trophic ulcers with plaster casts. Leprosy Review, 1955; 26: 107.

13 Bhasin D, Antia NH. Radical metatarsectomy for intractable plantar ulceration in leprosy. Leprosy Review 1972; 43: 53-8.

14 Anderson JG. Transverse metatarsal head resection a radical approach to the problem of forefoot ulceration. Leprosy Review, 1975; 46: 191.

15 Robertson, WS. Protective footwear for leprosy patients. Lepr India, 1956; 73: 28.

16 Antia NH. Plastic footwear for leprosy. Leprosy Review, 1990; 61: 73-8. 